\title{
Factors Influencing Sexual Behaviors among Thai Adolescents
}

\author{
Sitanan Srijaiwong ${ }^{1}$, Siriorn Sindhu ${ }^{2}$, Ameporn Ratinthorn ${ }^{3}$ \\ and Chukiat Viwatwongkasem ${ }^{4}$
}

\begin{abstract}
This cross-sectional analysis examines the factors influencing sexual behaviors, no-sex experience, safe sexual behaviors and unsafe sexual behaviors among adolescents, and the degree of sexual risk behaviors among sexually experienced adolescents by using web-based questionnaires. The participants were 3,192 Thai adolescents ages 15-19 and studying at secondary and vocational schools. Data were analyzed by using multinomial logistic regression analysis and multilevel regression analysis. Among all participants, 769 adolescents reported having had sexual experience defined as sexual intercourse (prevalence=24.09). Unsafe sexual behaviors escalated with age, enrollment in vocational school, greater perceived peer approval and sexual double standards. Unsafe sexual behaviors decreased with male gender, living with both parents having a higher sexual risk behavioral attitude and sexual message communication. The results revealed that school type was the greatest predictor influencing sexual risk behaviors followed by peer approval and sexual behaviors, type of family structure, living arrangements, sex, age, sexual risk behavioral attitude, sexual double standards and sexual message communication. In today's society, external environmental factors have greater influence on sexual risk behaviors, especially school environment. And each adolescent has different contexts related to sexual behaviors. Hence, we should consider differences in individual, family and school contexts when developing an effective health system that promotes sexual health and sexual risk behavior prevention among adolescents, one that will lead to decreased negative outcomes from sexual behaviors among adolescents.
\end{abstract}

Keywords: sexual risk behaviors, safe sexual behaviors, unsafe sexual behaviors, adolescents

1. PhD Candidate, Faculty of Nursing, Mahidol University, Thailand.

2. Faculty of Nursing, Mahidol University, Thailand. Email: siriorn.sin@mahidol.ac.th

3. Faculty of Nursing, Mahidol University, Thailand

4. Faculty of Public Health, Mahidol University, Thailand 


\section{Introduction}

Adolescent sexual risk behaviors represent one of the most significant social and public health concerns in both developed and developing countries (National AIDS Prevention and Alleviation Committee, 2010). Approximately 67 percent of new human immunodeficiency virus (HIV) and other sexually transmitted infections (STIs) are encountered in Asian adolescents. Adolescents ages 15-19 account for 50 percent of all patients with new STIs. In addition, approximately 16 million female adolescents ages 15-19 as well as 1 million female adolescents younger than 15 years of age give birth every year, mostly in developing countries (Centers for Disease Control and Prevention (CDC), 2016a). Sexual risk behaviors, including inconsistent use of condoms or birth control pills and having multiple sexual partners, among adolescents in developed countries can be controlled, even though they tend to have more sexual experiences than adolescents in developing countries. In the United States, 49 percent of all high school students were sexually experienced. Among them, 57 percent used condoms and 86 percent used a birth control method, while 70 percent of males and 57 percent of females reported safe sexual behaviors (CDC, 2016b).

In contrast, the problems of sexual risk behaviors among adolescents in developing countries have not been successfully addressed. Thailand is one developing country that remains confronted with health and social problems due to increased sexual risk behaviors. Among Thai adolescents, 28 percent of males and 23 percent of females enrolled in secondary schools had sexual experience. (Bureau of Epidemiology, 2015). Only 25 percent of them consistently used condoms; and according to a recent report, the adolescent pregnancy rate in Thailand has become the second highest in Southeast Asia (Bureau of Epidemiology, 2015). One question to be considered is the issue of identifying the factors influencing sexual behaviors among adolescents and the degree of sexual risk behaviors among sexually experienced adolescents in developing countries.

Adolescents are more likely to engage in sexual activity due to their pivotal phase of development (Bureau of Epidemiology, 2015; CDC, 2016a). Adolescents are in a period with elevated sexual drive and interest in sexual activities as they experience physical, psychological and emotional growth spurts. (Pusuwun, Wongyai \& Leekuan, 2013). Furthermore, hormones that influence sex drive peak at around the ages of 15-19. While social and environmental dynamics may be another major trigger leading adolescents to early engagement in sexual relationships, adolescents 
also want to disconnect from their families with the freedom to make independent decisions (McNeely \& Blanchard, 2009). Moreover, adolescents, who are in a pivotal phase of their development, are among the generation that most easily adopts these changes. Consequently some adolescents may be exposed to risk behaviors. The downside of the phenomenon of globalization has been the adoption of unhealthy lifestyles such as increasing unsafe sexual behaviors (National AIDS Prevention and Alleviation Committee, 2010).

Increased adolescent sexual risk behaviors in developing countries can be attributed to rapidly developing social urbanization, which has a direct impact on adolescents in terms of living arrangements and lifestyles (CDC, 2016b). This shift has changed the living conditions of many people (Rasamimari, Dancy, Talashek \& Park, 2007). Furthermore, more parents work outside their home due to current economic situations. This has resulted in a flow from rural to urban areas among adolescents seeking higher education. These adolescents may leave their homes early and become further separated from their parents (VanLandingham \& Trujillo, 2012). Moreover, family structures have changed with more single-parent households (Berge, Wall, Larson, Loth \& Neumark-Sztainer, 2013). Thus, many adolescents feel disconnected from their families. Despite recent changes, however, community norms and attitudes remain generally conservative in the belief that pre-marital sex or free sexual behaviors are considered acceptable for men.

Furthermore, sexuality remains a sensitive topic among adolescents themselves, as well as among the general public, especially in Asian society. Community norms and sexual attitudes have resulted in changing factors related to sexual behaviors among adolescents such as sexual message communication or information about sex (Kim \& Ward, 2007), sexual risk behavioral attitudes (Chaikoolvatana, Praditsathapron \& Kamkhieo, 2013) and sexual double standards with greater acceptance of sexual freedom for men than women (Collins, 2011). These factors have changed over time, and these social changes may affect the factors leading to increased sexual risk behaviors among adolescents.

Currently, socio-environmental factors have greater influence over sexual behaviors among adolescents, who spend a large amount of time at school. Sexual attitudes and behavior socialization from school influence adolescent sexual risk behavior (Shtarkshall, Santelli \& Hirsch, 2007). Each school type (secondary and vocational schools) has a different environment. Sex education teachers and peers are two important groups of people who are close to adolescents when it comes to the topic of sex. Sex education teachers have to manage sex education programs and teach or 
discuss sexual issues with adolescents, but scholars note that adolescents always spend more time with peers at school (Phunkham, Promprapat, Paisanautphong \& Samukkeekarom, 2010). Thus, peers become an important environmental factor for reinforcement, modeling and support affecting adolescent attitudes and behaviors, especially on sexual issues (Vivanco, Abubakar, Phillips-Howard \& Hunter, 2012).

That said, school plays an important role in providing sex education for adolescents (The United Nations Population Fund Thailand (UNFPA), 2013). Thus, each school tries to improve sex education by managing the educational programs and training sex education teachers for improvement in confidence about teaching sexual health topics. However, only a few studies have been conducted on the effectiveness of sex education programs and training of sex education teachers.

Many countries, like Thailand, are aware of sexual risk behavior issues. Over the past two decades, therefore, policy strategies and work plans have been devised for the prevention of sexual risk behaviors among adolescents. Interestingly, some countries have been able to solve this problem, but the prevalence of teenage pregnancies, STIs and HIV infections continues to escalate in many countries, including Thailand. Each country differs in the factors that drive policy implementation, as well as in the effectiveness of the policies and strategies. Some countries have not been about to solve this problem. Currently, the situation of sexual risk behaviors is uncontrolled in Thailand. Hence, an analysis of the factors influencing sexual behaviors and sexual risk behaviors is essential.

This cross-sectional analytical study analyzes the adolescent, family, peer and school factors influencing sexual behaviors and no-sex experience, as well as safe and unsafe sexual behaviors among adolescents, and the degree of sexual risk behaviors among sexually experienced adolescents. Results from this study provide new knowledge concerning socio-environmental and individual factors, taking into consideration the differences in individual and environmental contexts. Such knowledge can be useful for developing health systems based on prevention programs to reduce adolescent sexual risk behaviors, which can lead to decreased prevalence of HIV, other STIs and pregnancy among adolescents.

Data and Methods

This cross-sectional study explores the factors influencing no-sex experience, safe sexual behaviors and unsafe sexual behaviors among adolescents in Thailand. Two stages of random sampling were used to select 18 schools comprised of six suburban 
secondary schools, eight urban secondary schools and four vocational schools from provinces in the central region of the country (except Bangkok Metropolis).

The inclusion criteria included Thai adolescents ages 15-19 and studying in grades 10-12 at the selected urban or suburban secondary public schools or vocational public schools with the ability to communicate in Thai and sufficient computer literacy to complete the questionnaire. Additionally, the research team collected data from sex education teachers who had experience teaching sexual health education and the ability to communicate in Thai. Altogether, 110 sex education teachers participated in the study.

To collect data from adolescents, the research team used a web-based, selfadministered questionnaire through a free Internet program on Google Drive, an appropriate means of data collection for sensitive issues. Researchers then used a paper-based questionnaire to collect data from teachers.

\section{Instruments Used to Collect Data from Adolescents:}

1) General information on personal characteristics of adolescents and their families, which included age, sex, living arrangements and type of family structure;

2) Sexual risk behavioral attitude questionnaire: Eight items on the Sexual Risk Behavior Belief Scale (SRBBS) developed by Srisuriyawet (2006), inquiring about perceived sexual norms, perceived multiple partner norms and perceived birth control use. Cronbach's alpha coefficient was 0.90 for the pilot group;

3) Perceived sexual message communication questionnaire: 22 items on the Childhood and Adolescent Sexual Messages Scale (Trinh, Ward, Day, Thomas $\&$ Levin, 2013) assessed the perception of adolescents who received sexual messages from their parents. This instrument was translated into Thai using the back translation method to ensure culturally equivalent versions of the instrument in the Thai language. Three experts assessed the content validity of this questionnaire. The inter-rater agreement (IR) for the items was between 0.94-1.00, and the mean item IR was 0.96. The content validity index (CVI) for the items was between 0.67-1.00, and the mean item CVI was 0.96. Cronbach's alpha coefficient was 0.89 for the pilot group; 
4) Perceived sexual double standards questionnaire: 26 items on sexual double standards assessed adolescent adherence to traditional sexual double standards (SDS) by using the Sexual Double Standard Scale (Muehlenhard \& Quackenbush, 2011). This instrument measures the acceptance of sexual double standards. It was translated into Thai using the back translation method to ensure culturally equivalent versions of the instrument in the Thai language. The IR and CVI for the items and the mean item were 1.00 each. Cronbach's alpha coefficient was 0.90 for the pilot group;

5) Peer approval and sexual behavior questionnaire: This instrument was developed by Srisuriyawet (2006) to assess perceptions regarding peer influence about sexual behavior and protection behavior. Cronbach's alpha coefficient was 0.94 for the pilot group; and

6) The Sexual Risk Behavior questionnaires developed by Srisuriyawet (2006) to assess the degree of the sexual risk behaviors, including having anal or vaginal sexual intercourse within the past three months, using a condom at first sexual encounter, use of condoms in recent intercourse, inconsistent use of dual protection (birth control pill and condoms), having multiple sexual partners over the last year, and having multiple sexual partners over the last three months. Cronbach's alpha coefficient was 0.89 .

\section{Instruments Used to Collect Data from Sex Education Teachers:}

1) General data on schools and teachers: The general data of the schools consisted of school type, sex education program and the sex education training;

2) Confidence about Teaching Sexual Health Topics questionnaire: 22 items on the Sex Education Confidence Scale (SECS) (Tietjen-Smith, Balkin \& Kimbrough, 2014) assessed confidence about the teachers' ability to discuss topics in the classroom context. This instrument was translated into Thai using the back translation method to ensure culturally equivalent versions of the instrument in the Thai language. The item and mean item IR and CVI were 1.00 each. Cronbach's alpha coefficient was 0.93 for the pilot group. 


\section{Data Collection}

The research team collected all data after receiving permission from the Mahidol University Institutional Review Board, Nursing (IRB-NS). Researchers then coordinated with the directors of the schools and made appointments with the adolescent participants to collect data online using the schools' computer labs. The research team then gave the study information to the participants. Once all potential participants understood, they clicked on "willing to participate in this research," which had to be marked before the first item of the questionnaires could be opened. Next, participants completed the internet-based questionnaires. For sex education teachers, the researchers gave research information to the participants. Once the participants understood, the researchers sought their consent to participate in the study. The teachers then signed the consent form to participate in the study and expressed willingness to complete the questionnaires. Data were collected from March to December 2016.

\section{Data Analysis}

Descriptive statistics were used to describe general data, individual-level factors, socio-environmental factors and sexual risk behaviors among both adolescents and teachers. Multinomial logistic regression analysis was employed to determine the predictors influencing sexual behaviors among adolescents with no sexual experience, safe sexual behaviors and unsafe sexual behaviors. Using the findings from multinomial logistic regression analysis, the researchers used multi-level regression analysis to analyze the factors influencing the degree of sexual risk behaviors among sexually experienced adolescents.

\section{Results}

A total of 3,437 male and female adolescents were invited to participate; and 3,423 questionnaires (response rate $=99.6$ percent) were returned online. There were 3,192 questionnaires that met the inclusion criteria for the study (93.3 percent).

Among the participants, there were 2,423 adolescents with no-sexual experience (75.9 percent), 109 adolescents with safe sexual behaviors (3.4 percent) and 660 adolescents with unsafe sexual behaviors (20.7 percent). Among those with sexual 
experiences ( 769 adolescents or 24.1 percent), 280 were male (36.4 percent) and 489 were female (63.6 percent). The ages of the participants were 15-19 (mean=16.5, S.D. $=0.9$ ). A higher prevalence of sexual experience was found among adolescents who lived away from parents (prevalence 37.9), lived in single-parent households (prevalence 32.9), and were older. The adolescents enrolled in vocational schools were older and more likely to live away from parents and live in single-parent households more than those enrolled in secondary school (Table 1).

Table 1: Number, Percentage and Prevalence of Demographic Characteristics of the Participants Categorized by all Participants and Sexually Experienced Participants $(\mathrm{N}=3,192)$

\begin{tabular}{|c|c|c|c|c|c|}
\hline \multirow[t]{2}{*}{ Participant Characteristics } & \multicolumn{2}{|c|}{$\begin{array}{l}\text { Total Number of } \\
\text { Participants } \\
(\mathrm{N}=3,192)\end{array}$} & \multicolumn{3}{|c|}{$\begin{array}{c}\text { Number of Sexually } \\
\text { Experienced Participants } \\
(\mathrm{N}=769)\end{array}$} \\
\hline & $\mathrm{N}$ & $\%$ & $\mathrm{~N}$ & $\%$ & Prevalence \\
\hline \multicolumn{6}{|l|}{ Age } \\
\hline 15 & 601 & 18.8 & 58 & 7.5 & 9.7 \\
\hline 16 & 11,029 & 32.2 & 164 & 21.3 & 15.9 \\
\hline 17 & 11,060 & 33.2 & 352 & 46.0 & 33.2 \\
\hline 18 & 458 & 14.3 & 169 & 22.0 & 36.9 \\
\hline 19 & 44 & 1.4 & 24 & 3.1 & 54.6 \\
\hline Mean & 16.5 & & 16.9 & & \\
\hline S.D. & 0.9 & & 0.9 & & \\
\hline \multicolumn{6}{|l|}{ Sex } \\
\hline Male & 1,153 & 36.1 & 280 & 36.4 & 24.3 \\
\hline Female & 2,039 & 63.9 & 489 & 63.6 & 24.0 \\
\hline \multicolumn{6}{|l|}{ Living arrangements } \\
\hline Living with parents & 2,944 & 92.2 & 675 & 87.8 & 22.9 \\
\hline Living with the others & 248 & 7.8 & 94 & 12.2 & 37.9 \\
\hline \multicolumn{6}{|l|}{ Types of family structure } \\
\hline Two parents & 2,171 & 68.0 & 433 & 56.3 & 19.9 \\
\hline Single parent & 1,021 & 32.0 & 336 & 43.7 & 32.9 \\
\hline
\end{tabular}

Table 2 shows the summary of aggregate scores on the risk among sexually experienced participants. Female adolescents who were sexually experienced were at a higher risk than men, especially in terms of having intercourse within the past three months, as well as inconsistent use of condoms and birth control pills. However, the 
sexually experienced male adolescents had more sexual partners than the females. Most of the adolescents with unsafe sexual behaviors had more favorable attitudes toward sexual risk behaviors ( 79.8 percent), greater acceptance of sexual freedom for men than women (63.6 percent), and stronger approval of close friends with sexual risk behaviors ( 89.2 percent). Furthermore, most of the adolescents with safe sexual behaviors had more perceived sexual message communication, the perception of adolescents who received sexual messages from their parents (98.2 percent).

Table 2: Summary of Aggregate Scoring Characteristics of Sexual Risk Behaviors $(\mathrm{N}=769)$

\begin{tabular}{|c|c|c|}
\hline \multirow[t]{2}{*}{ Sexual Risk Behaviors } & \multicolumn{2}{|c|}{$\begin{array}{l}\text { Number of sexually } \\
\text { experienced students } \\
(\mathrm{N}=769)\end{array}$} \\
\hline & $\mathrm{N}$ & $\%$ \\
\hline \multicolumn{3}{|l|}{ Sexual Activity } \\
\hline $\begin{array}{l}\text { Having sexual experience, but not having intercourse over } \\
\text { the past } 3 \text { months }\end{array}$ & 231 & 30.0 \\
\hline $\begin{array}{l}\text { Having sexual experience and having intercourse over the } \\
\text { past } 3 \text { months }\end{array}$ & 538 & 70.0 \\
\hline \multicolumn{3}{|l|}{ Inconsistent Condom Use } \\
\hline Using condoms at both first and most recent intercourse & 357 & 46.4 \\
\hline Using condoms at first or most recent intercourse & 271 & 35.2 \\
\hline Not using condoms at first or most recent intercourse & 141 & 18.3 \\
\hline \multicolumn{3}{|l|}{ Frequency of Condom Use over the Past 3 Months } \\
\hline Every time & 166 & 30.8 \\
\hline Sometimes & 272 & 50.5 \\
\hline Never & 101 & 18.7 \\
\hline \multicolumn{3}{|c|}{ Frequency of Use Birth Control Pills and condoms during the Past 3 Months } \\
\hline Every time & 98 & 18.2 \\
\hline Sometimes & 186 & 34.5 \\
\hline Never & 255 & 47.3 \\
\hline \multicolumn{3}{|l|}{ Multiple Partners } \\
\hline $\begin{array}{l}\text { Did not have two or more sexual partners over past year or } \\
\text { past } 3 \text { months }\end{array}$ & 500 & 65.0 \\
\hline $\begin{array}{l}\text { Having two or more sexual partners over last year or past } 3 \\
\text { months }\end{array}$ & 195 & 25.4 \\
\hline $\begin{array}{l}\text { Having two or more sexual partners over past year and past } \\
3 \text { months }\end{array}$ & 74 & 9.6 \\
\hline
\end{tabular}


Most of the 110 sex education teachers were 51-60 years old (39.1 percent) with a mean age of $43.1(\mathrm{SD}=12.4)$. More than half of the teachers were female (56.4 percent), and approximately three in four teachers had high scores on confidence about teaching sexual health topics. One out of three of the sex education teachers had never participated in sex education training (32.7 percent); and the total number of students per the total number of sex education teachers who had had sex education training at each type of school differed within a range of 353.7-1,302.0 for suburban secondary schools, a range of 213.2-741.0 for urban secondary schools and a range of 987.0-2,802.0 for vocational schools. The studies divided sex education programs into the following two categories: Six schools were found to have a sex education program (33.3 percent) and 12 schools had implemented health education program or integrated sex education contents into health education subject (66.7 percent).

The results of the multinomial multivariate logistic regression analysis for predicting sexual behaviors among adolescents $(n=3,192)$ are presented in Tables 3 and 4 . The Nagelkerke's $R^{2}$ was shown at 0.74 or 74 percent of the variance in sexual behaviors predicted by variables (Chi square $=2,504.021, \mathrm{df}=28, \mathrm{p}<0.001$ ). The safe sexual behaviors were higher in males compared to females (OR=1.712, 95\% CI [1.0232.863]); adolescents living with parents compared to those living with other arrangements (OR=1.141, 95\% CI [1.069-1.288]), living with two parents compared to living with single parent $(\mathrm{OR}=1.260,95$ percent $\mathrm{CI}$ [1.059-1.558]), and higher scores for sexual risk behavioral attitudes (OR=1.586, 95\% CI [1.0161.961] and perceived sexual message communication (OR=1.312, 95\% CI [1.2741.352]. Safe sexual behaviors decreased as students grew older $(\mathrm{OR}=1.467,95 \% \mathrm{CI}$ [0.832-1.903]) and were enrolled in vocational schools (OR=0.825, 95\% CI [0.674$0.925]$ ). However, perceived sexual double standards, sex education programs, sexual education training, confidence about teaching sexual health topics and peer approval and sexual behavior were unable to predict safe sexual behaviors (Table 3). 
Table 3: Multinomial Multivariate Logistic Regression Model of Predictors of Safe Sexual Behaviors among Adolescents $(\mathrm{N}=3,192)$

\begin{tabular}{|c|c|c|c|c|c|c|c|}
\hline \multirow[t]{2}{*}{ Variables } & \multirow[t]{2}{*}{ B } & \multirow[t]{2}{*}{ SE } & \multirow[t]{2}{*}{ Wald } & \multirow[t]{2}{*}{$d f$} & \multirow[t]{2}{*}{ AOR } & \multicolumn{2}{|c|}{$\begin{array}{l}95 \% \mathrm{CI} \text { for } \\
\mathrm{EXP}(\mathrm{B})\end{array}$} \\
\hline & & & & & & Lower & Upper \\
\hline Age & $-0.384^{* *}$ & 0.133 & 8.373 & 1 & 1.467 & 0.832 & 1.903 \\
\hline \multicolumn{8}{|l|}{ Sex } \\
\hline Female & Reference & & & & & & \\
\hline Male & $0.537^{*}$ & 0.263 & 4.188 & 1 & 1.712 & 1.023 & 2.863 \\
\hline \multicolumn{8}{|l|}{ Living arrangement } \\
\hline Living with the others & Reference & & & & & & \\
\hline Living with parents & $1.961^{* * *}$ & 0.365 & 28.897 & 1 & 1.141 & 1.069 & 1.288 \\
\hline \multicolumn{8}{|l|}{ Type of family structure } \\
\hline Single parent & Reference & & & & & & \\
\hline Two parents & $0.274^{* *}$ & 0.257 & 1.139 & 1 & 1.260 & 1.059 & 1.558 \\
\hline Sexual risk behavioral attitude & $0.014^{* *}$ & 0.037 & 0.147 & 1 & 1.586 & 1.016 & 1.961 \\
\hline \multicolumn{8}{|l|}{ communication } \\
\hline \multicolumn{8}{|l|}{ Type of school } \\
\hline Suburban secondary school & Reference & & & & & & \\
\hline Urban secondary school & -0.646 & 0.561 & 1.326 & 1 & 0.524 & 0.174 & 1.574 \\
\hline Vocational school & $-0.203^{* *}$ & 0.305 & 0.444 & 1 & 0.825 & 0.674 & 0.925 \\
\hline \multicolumn{8}{|l|}{ Sex education program } \\
\hline $\begin{array}{l}\text { Implementation of health } \\
\text { education subjects }\end{array}$ & Reference & & & & & & \\
\hline Sex education subjects & 0.966 & 0.370 & 6.820 & 1 & 2.627 & 1.272 & 5.422 \\
\hline Sexual education training & 0.000 & 0.000 & 0.008 & 1 & 1.000 & 0.999 & 1.001 \\
\hline $\begin{array}{l}\text { Confidence about teaching } \\
\text { sexual health topics }\end{array}$ & -0.025 & 0.015 & 2.894 & 1 & 0.975 & 0.948 & 1.004 \\
\hline $\begin{array}{l}\text { Peer approval and sexual } \\
\text { behavior }\end{array}$ & -0.017 & 0.091 & 0.036 & 1 & 0.983 & 0.823 & 1.174 \\
\hline Intercept & $-12.766^{* * *}$ & 2.604 & 24.042 & 1 & & & \\
\hline
\end{tabular}


Unsafe sexual behaviors also increase with age (OR=1.989, 95\% CI [1.672-2.365]), enrollment in vocational schools ( $\mathrm{OR}=1.844,95 \% \mathrm{CI}[1.215-2.797])$, higher scores for peer approval and sexual behavior (OR=1.225, 95\%CI [1.083-1.385]) and higher scores for perceived sexual double standards (OR=1.019, 95\%CI [1.0061.253]). Unsafe sexual behavior decreased when adolescents were males compared to females (OR=0.719, 95\% CI [0.508-1.016]), living with parents compared to living with the others $(\mathrm{OR}=0.562,95 \% \mathrm{CI}[0.323-0.978])$ and living with two parents compared to living with single parent ( $\mathrm{OR}=0.714,95 \% \mathrm{CI}[0.510$ - 0.999]), having a higher score for sexual risk behavioral attitude (OR=0.932, 95\% CI [0.890-0.976]) and having a higher score for perceived sexual message communication (OR=0.299, 95\% CI [0.272-0.328]). However, sex education programs, sexual education training and confidence about teaching sexual health topics were unable to predict unsafe sexual behaviors (Table 4). 
Table 4: Multinomial Multivariate Logistic Regression Model of Predictors of Unsafe Sexual Behaviors among Adolescents $(\mathrm{N}=3,192)$

\begin{tabular}{|c|c|c|c|c|c|c|c|}
\hline \multirow[t]{2}{*}{ Variables } & \multirow[t]{2}{*}{ B } & \multirow[t]{2}{*}{$\mathrm{SE}$} & \multirow[t]{2}{*}{ Wald } & \multirow[t]{2}{*}{$\mathrm{df}$} & \multirow[t]{2}{*}{ AOR } & \multicolumn{2}{|c|}{$\begin{array}{l}95 \% \mathrm{CI} \text { for } \\
\operatorname{EXP}(\mathrm{B})\end{array}$} \\
\hline & & & & & & Lower & Upper \\
\hline Age & $0.687^{* * *}$ & 0.088 & 60.500 & 1 & 1.989 & 1.672 & 2.365 \\
\hline \multicolumn{8}{|l|}{ Sex } \\
\hline Female & Reference & & & & & & \\
\hline Male & $-0.331^{*}$ & 0.177 & 3.502 & 1 & 0.719 & 0.508 & 1.016 \\
\hline \multicolumn{8}{|l|}{ Living arrangement } \\
\hline Living with the others & Reference & & & & & & \\
\hline Living with parents & $-0.576^{*}$ & 0.282 & 4.160 & 1 & 0.562 & 0.323 & 0.978 \\
\hline \multicolumn{8}{|l|}{ Type of family structure } \\
\hline Single parent & Reference & & & & & & \\
\hline Two parents & $-0.337^{*}$ & 0.172 & 3.857 & 1 & 0.714 & 0.510 & 0.999 \\
\hline Sexual risk behavioral attitude & $-0.070^{* *}$ & 0.023 & 9.103 & 1 & 0.932 & 0.890 & 0.976 \\
\hline $\begin{array}{l}\text { Perceived sexual message } \\
\text { communication }\end{array}$ & $-0.262^{* * *}$ & 0.011 & 570.115 & 1 & 0.299 & 0.272 & 0.328 \\
\hline $\begin{array}{l}\text { Perceived sexual double } \\
\text { standard }\end{array}$ & $0.019^{*}$ & 0.017 & 1.271 & 1 & 1.019 & 1.006 & 1.253 \\
\hline \multicolumn{8}{|l|}{ Type of school } \\
\hline Suburban secondary school & Reference & & & & & & \\
\hline Urban secondary school & 0.481 & 0.334 & 2.072 & 1 & 1.617 & 0.840 & 3.111 \\
\hline Vocational school & $0.612^{* *}$ & 0.213 & 8.276 & 1 & 1.844 & 1.215 & 2.797 \\
\hline \multicolumn{8}{|l|}{ Sex education program } \\
\hline $\begin{array}{l}\text { Implementation of health } \\
\text { education subjects }\end{array}$ & Reference & & & & & & \\
\hline Sex education subjects & 0.678 & 0.257 & 6.935 & 1 & 1.970 & 1.189 & 3.263 \\
\hline Sexual education training & 0.000 & 0.000 & 0.000 & 1 & 1.000 & 1.000 & 1.000 \\
\hline $\begin{array}{l}\text { Confidence about teaching } \\
\text { sexual health topics }\end{array}$ & -0.033 & 0.011 & 9.394 & 1 & 0.968 & 0.948 & 0.988 \\
\hline $\begin{array}{l}\text { Peer approval and sexual } \\
\text { behavior }\end{array}$ & $0.203^{* *}$ & 0.063 & 10.488 & 1 & 1.225 & 1.083 & 1.385 \\
\hline Intercept & $-12.998^{* * *}$ & 1.832 & 50.336 & 1 & & & \\
\hline
\end{tabular}

The results of the multi-level regression analysis of the degree of sexual risk behaviors among sexually experienced adolescents are presented in Table 5. For the individual level factors, the scores for sexual risk behaviors increased as a result of the following seven predictors: Older sexually experienced adolescents $(B=0.232, p<0.001)$, female $(B=0.289, p<0.05)$, living away from parents' homes $(B=0.562, p<0.01)$, living in a single parent household $(B=0.623, p<0.01)$, higher scores for greater acceptance of 
sexual double standards $(B=0.045, p<0.001)$, lower scores for attitude toward sexual risk behaviors $(B=-0.109, p<0.001)$, and perceived sexual message communication $(B=-0.017, p<0.01)$. For the socio-environment factors, the scores for sexual risk behaviors increased as a result of the following two predictors: Enrollment in vocational schools $(B=0.864, p<0.01)$ and higher scores on peer approval and sexual behavior $(B=-0.709, p<0.001)$. However, sex education programs, sex education training and confidence about teaching sexual health topics were unable to significantly predict sexual risk behaviors.

Table 5: Multi-level Regression Model of Predictors of Sexual Risk Behaviors among Sexual Experience Adolescents (N=769)

\begin{tabular}{|c|c|c|c|c|c|}
\hline \multirow{2}{*}{ Fixed effect } & \multirow[t]{2}{*}{ Estimate } & \multirow[t]{2}{*}{$\mathrm{SE}$} & \multicolumn{3}{|c|}{ [95\%Conf. Interval] } \\
\hline & & & & & \\
\hline Intercept $(\boldsymbol{\beta})$ & $10.102^{* * *}$ & 1.847 & 6.481 & to & 13.723 \\
\hline \multicolumn{6}{|l|}{ Individual-level factors } \\
\hline Age & $0.232^{* * *}$ & 0.067 & 0.102 & to & 0.363 \\
\hline Sex & $0.289^{*}$ & 0.126 & 0.041 & to & 0.537 \\
\hline Living arrangement & $0.562^{* *}$ & 0.197 & 0.275 & to & 1.049 \\
\hline \multicolumn{6}{|l|}{ Type of family structure } \\
\hline Type 1 (Two parents) & Reference & & & & \\
\hline Type 2 (Single parent) & $0.623^{* *}$ & 0.263 & 0.207 & to & 1.239 \\
\hline Sexual risk behavioral attitude & $-0.109^{* * *}$ & 0.018 & -0.144 & to & -0.075 \\
\hline Perceived sexual double standard & $0.045^{* * *}$ & 0.011 & 0.023 & to & 0.066 \\
\hline Perceived sexual message communication & $-0.017^{* *}$ & 0.006 & -0.030 & to & -0.005 \\
\hline \multicolumn{6}{|l|}{ Socio environment-level factors } \\
\hline \multicolumn{6}{|l|}{ School type } \\
\hline Type 1: suburban secondary school & Reference & & & & \\
\hline Type 2: urban secondary school & 0.231 & 0.713 & -0.828 & to & 1.166 \\
\hline Type 3: vocational schools & $0.864^{* *}$ & 0.299 & 1.378 & to & 1.750 \\
\hline Peer approval and sexual behavior & $-0.709^{* * *}$ & 0.115 & -0.734 & to & -0.285 \\
\hline \multicolumn{6}{|l|}{ Random effect } \\
\hline Residual & 2.476 & 0.130 & 2.234 & to & 2.744 \\
\hline S.D. (cons) & 0.363 & 0.171 & 0.144 & to & 0.915 \\
\hline S.D. (Urban secondary school) & 0.934 & 1.625 & 0.031 & to & 28.257 \\
\hline S.D. (Vocational schools) & 0.161 & 0.555 & 0.001 & to & 140.679 \\
\hline S.D. (Peer approval and sexual behavior) & 0.002 & 0.005 & 0.001 & to & 0.012 \\
\hline \multicolumn{6}{|c|}{$\mathrm{LL}=-1477.098 \mathrm{AIC}=2994.196 \mathrm{BIC}=3087.097$} \\
\hline
\end{tabular}




\section{Discussion}

Today, in some developing countries, particularly in Thailand, male and female adolescents have equal sexual experience. Interestingly, the present study shows that female sexually experienced adolescents have a higher degree of sexual risk behaviors than males. Although the acceptance of sexual rights have increased (Morrison, 2004), some people continue to live by traditional sexual norms. Adolescents' views are shaped by current social norms as well as social information they receive over the course of their lifetimes (Austin, 2011). Some female adolescents may not receive safe sex information messages, for example, and instead receive only sexual abstinence messages.

Some young women's desires have been shifting away from traditional sexual norms, while their behaviors continue to comply with traditional roles (Fazio \& RoskosEwoldsen, 2005), regardless of their internal desires to act differently. This results in increased sexual risk behavior among female adolescents due to the inability to motivate boyfriends to use condoms (Chirawatkul, Kumdee, Jongudomkarn \& Kotanara, 2012). However, these female adolescents do not feel that they were forced into having sexual relationships, because most of the female adolescents were willing to engage in sexual relationships without using condoms (Mchunu, Peltzer, Tutshana \& Seutlwadi, 2012) and have unprotected sex with their partners (Srisuriyawet, 2006). The above findings concur with the report of the Bureau of Epidemiology (2015), stating that condom use has declined among female adolescents who have had sexual relationships with their partners as an expression of love.

As for the predictors of sexual behaviors and sexual risk behaviors, rapid urban development poses direct impact on adolescent sexual behaviors. School type and peers were the most important factors influencing unsafe sexual behaviors. These findings show that external environmental factors have greater influence on sexual risk behaviors, possibly related to school location and specific characteristics of schools and students. The findings concur with previous studies that different school types (secondary and vocational schools) have different environments (Augsornrat, Perngmark \& Jansawang, 2009; Ingkathawornwong, Kritcharoen, Pol-in \& Charoonsak, 2007).

School type appears to be the strongest predictor of sexual behaviors in adolescents ages 15-19 (Fentahun, Assefa, Alemseged \& Ambaw, 2012). Vocational schools are 
educational institutes emphasizing practice or job training out of the classroom. Thus, students are closely involved with the external environment. Moreover, learning management systems have more freedom and flexible lecture times than secondary schools (Augsornrat et al., 2009; Ingkathawornwong et al., 2007). In addition, thegeographic settings of vocational schools in Thailand are mainly in urban areas, while the geographic settings of secondary schools include both suburban and urban schools. Adolescents whose schools are located in urban areas have been found to be three times more likely to have had sexual experience than those in rural schools (Ajuwon, Olaleye, Faromoju \& Ladipo, 2006).

Peer approval, greater understanding about peer sexual behavior and approval of close peers' sexual risk behaviors are variables that can predict unsafe sexual behavior. These findings concur with a study by Srisuriwat (2006), who discovered that peer influence had a strong effect on sexual risk behaviors. This present study shows that adolescents who have a greater understanding of their peers' sexual behaviors are more likely to be influences by their peers, especially adolescents in vocational schools. Vocational schools have higher numbers of sexually experienced adolescents and more free time with peers. Thus, the adolescents in vocational schools have more peer pressure influence. Vivanco et al. (2012) found that most adolescents learned sexual activity from their peers. This concurs with previous studies in Thailand indicating that peers influence non-use of contraceptives (Fongkaew et al., 2011) and decisions to go to night clubs (Ingkathawornwong et al., 2007). Thus, peers become an important environmental factor, especially concerning unsafe sexual behaviors.

In addition, more sexually experienced adolescents were found in vocational schools because they were older, living away from parents and living in single-parent family structures more often than those studying in secondary schools. As mentioned above, a higher prevalence of sexual experience was revealed in older adolescents, who had more girlfriends or boyfriends leading to engagement in sexual relationships. Most of the adolescents were less likely to use condoms or contraceptives and more were sexually active with their partners. Additionally, older adolescents were found to live away from home (Pusuwun et al., 2013), while more sexually experienced adolescents enrolled in vocational schools were separated from their families, especially during vocational training periods, and had single parents. Previous studies have shown that adolescents living with their parents have more suitable decisionmaking processes due to family support. Adolescents who have high perceived family support are more likely to delay having sex, exercise consistent condom use (Abebe, 
Tsion \& Netsanet, 2013), engage less frequently in sexual activity and have less peer pressure to have sex (Asrat, 2014).

A previous study by Sturgeon (2008) showed that adolescents living with two biological parents were less sexually experienced than those living with single parents. As mention above, although adolescents spend more time outside their homes, their families or parents continue to influence their sexual behaviors. Because families are the primary sources of norms and role models, behaviors learned within family environments are more likely to provide a foundation for subsequent attitudes and behaviors.

Sex education programs, sex education training among teachers and confidence about teaching sexual health topics were unable to significantly predict both sexual behaviors and sexual risk behaviors among adolescents. These findings were inconsistent with previous evidences (Tietjen-Smith et al., 2014; Vivanco, et al., 2012). Numerous reasons may explain these results. First, effective sex education programs are rare in Thailand. Most programs focus more on imparting scientific knowledge than encouraging attitudes toward sexual issues and improving negotiation and decision-making skills (Tanasugarn, Kengkarnpanich \& Kaeodumkoeng, 2012). Another gap is that comprehensive sex education has not yet been taught in all schools nationwide. Due to insufficient political stability, there is no clear policy commitment and implementation at the ministry and school levels. Since 2003, the sexuality education curriculum has involved the Teen Path Project, developed by the Program for Appropriate Technology in Health (PATH). PATH has succeeded in institutionalizing sex education curriculum in schools by using comprehensive sex education programs, but only $4 \%$ of all schools have adopted the sexuality education curriculum under the PATH project (Boonmongkon \& Thaweesit, 2008).

Secondly, confidence about teaching sexual health topics may indirectly impact sexual risk behaviors such as the effects on knowledge and understanding of sexual topics in the classroom (Tietjen-Smith et al., 2014). And teachers' confidence about teaching sexual health may be dependent on their training. In Thailand, the Ministry of Public Health, Ministry of Education and PATH conducted a project to improve sex education by increasing the competency of sex education teachers and developing education quality management in schools. However, the project was not successful in improving teachers attitudes toward sexual behaviors among adolescents. Teachers were encouraged to consider which sexual topics they should teach or discuss with adolescents depending on their attitudes and beliefs, which led 
to inconsistent topics or content of sex education (Vuttanont, Greenhalgh, Griffin $\&$ Boynton, 2006). This conflict has resulted in reduced effectiveness of sex education in school.

Lastly, the ratio of sex education training teachers to the total number of students was at a wide range $(1: 353-2,802)$, although limited studies have been conducted about this issue in Thailand. Thai sex education teachers report having taught sex education to numerous students, particularly at vocational schools. In international studies, the appropriate ratio of teacher to students should be 1:43. Sex education teachers could discuss and make suggestions about sexual issues, if the ratio of trained teachers to the total number of students is no higher (Mulama, 2006).

The effectiveness of sex education in Thai schools should be strengthened. Sex education teachers are the most important factor leading to successful sex education outcomes. In urban settings, adolescents are more likely to be separate from their parents and spend more time at school. Moreover, they have to deal with many myths about adolescent physical, hormonal and physiological changes, while no one is available to guide and explain these natural changes to them. Hence, attitudes toward sexual issues among sex education teachers are a key factor in improving sex education in schools in order to reduced adolescent sexual risk behaviors. According to an international study, teachers who received training showed more positive attitudes about sexual issues (Goldman, 2011; Im \& Park, 2014; Ramiro \& Matos, 2008). A previous study in Thailand found that only teachers who received training showed more knowledge about sexual health (Tanasugarn et al., 2012). Sex education training programs should be concerned with changing attitudes toward adolescent sexual behaviors. According to an international study, teachers with more positive attitudes about adolescent sexual behaviors were associated with decreases in sexual risk behaviors among adolescents ( $\operatorname{Im} \&$ Park, 2014). Thus, sex education can be improved by providing effective sex education training.

Concerning research limitations, this study used a cross-sectional research design, which means a causal relationship cannot be drawn. Therefore, the findings are unable to determine correlations between the independent and dependent variables, nor are the findings able to indicate cause and effect. This study also included only adolescents with heterosexual experience. Thus, the patterns of sexual practices might not be representative of homosexual relationships. Recently, more complex sexual patterns with more variation have emerged. Therefore, more studies should be conducted among adolescents at universities and/or out of school. 


\section{Conclusion and Recommendations}

The findings of this study indicate that, safe and unsafe sexual behaviors, and degree of sexual risk among adolescents were influenced by individual and environmental factors. School type was found to be the most powerful predictor. These findings indicated that external environment is an important factor that influences sexual risk behaviors among adolescents. School type and peer group influence were found to be the factors influencing sexual risk behaviors. For individual-level factors, type of family structure was found to be the most powerful predictor, followed by living arrangements, sex and age. Moreover, attitudes toward sexual risk behaviors, perceived sexual double standards and perceived sexual message communication were the predictors influencing sexual risk behaviors.

Solutions for sexual risk behaviors among adolescents should therefore consider school, family and individual contexts. School environment is the key factor in finding solutions to this problem. Sex education in schools needs to be improved. Attitudes toward sexual issues among sex education teachers are an important factor in steering effective sex education in schools. Programs should be concerned not only with improving knowledge and/or attitudes toward sex education, but also with changing attitudes toward sexual behaviors among adolescents. And due to peer influences on sexual risk behavior, peer group support or adolescent-friendly clinics are necessary in schools for sharing and sending positive sexual messages to adolescents. Additionally, parents need to be supported in discussing sexual relationships with their children. It is necessary to emphasize more positive sexual communications between adolescents and their parents, especially in families with single parents.

These findings can be useful in improving the health system concerning the prevention of sexual risk behaviors based on differences in the individual and environmental contexts, as well as management of the school environment, which can lead to decreased prevalence of HIV, other STIs and pregnancy among Thai adolescents. 


\section{References}

Abebe, M., Tsion, A. \& Netsanet, F. (2013). Living with parents and risky sexual behaviors among preparatory school students. African Health Sciences, 13(2), 59-68. DOI: 10.4314/ahs.v13i2.42

Ajuwon, A. J., Olaleye, A., Faromoju, B. \& Ladipo, O. (2006). Sexual behavior and experience of sexual coercion among secondary school students in three states in North Eastern Nigeria. BMC Public Health, 6, 1-10. DOI: 10.1186/14712458-6-310

Asrat, A. (2014). Assessment of sexual risk behaviors of in-school youth: Effect of living arrangement of students. American Journal of Health Research, 2(2), 7883. DOI: $10.11648 /$ j.ajhr.20140202.18

Augsornrat, S., Perngmark, P. \& Jansawang, W. (2009). Family structure, family functions and sexual risk behaviors among female junior high-school students, Muang district Nakhon Si Thammarat Province. Journal of Health Science, $18(5), 736-744$.

Austin, C. A. (2011). The sexual double standard: Cultural myth or influential script in relation to the sexual assertiveness of men and women in two generational cohorts. (Unpublished doctoral dissertation). Faculty of Graduate and Postdoctoral Affairs, Carleton University at Canada.

Berge, J. M., Wall, M., Larson, N., Loth, K. A. \& Neumark-Sztainer, D. (2013). Family functioning: associations with weight status, eating behaviors, and physical activity in adolescents. Journal of Adolescent Health, 52(2), 351-357.

Boonmongkon, P. \& Thaweesit, S. (2008) Sexuality education in Thailand: How far do we need to go? Retrieved from http://www.teenpath.net/data/rresearch/00010/tpfile/00001.pdf

Bureau of Epidemiology. (2015). Surveillance reports of behaviors related to HIV infection among Thai student. Nonthaburi, Thailand: Bureau of Epidemiology, Department of Disease Control Ministry of Public Health.

Centers for Disease Control and Prevention. (2016a). Sexual risk behavior guidelines \& resources. Retrieved from http://www.cdc.gov/healthyyouth/sexualbehaviors/strategies.htm

Centers for Disease Control and Prevention. (2016b). Youth risk behavior surveillance - United States 2015. Morbidity and Mortality Weekly Report, 63, (SS-4).

Chaikoolvatana, C., Praditsathaporn, C. \& Kamkhieo, W. (2013). Predictors of sexual risk behavior among adolescents in Phayao province. Journal of Nursing and Education, 6, 105-115. 
Chirawatkul, S., Kumdee, B., Jongudomkarn, D. \& Kotanara, I. (2012). Situation of teenage pregnancy: Perception among adolescent in 7 provinces of Thailand. Journal of Health Science, 21, 865-877.

Collins, R. L. (2011). Content analysis of gender roles in media: Where are we now and where should we go? Sex Roles, 64, 290-298. DOI: 10.1007/s11199-0109929-5

Fazio, R. H. \& Roskos-Ewoldsen, D. R. (2005). Acting as we feel: When and how attitudes guide behavior. In T. C. Brock \& M. C. Green (Eds.), Persuasion: Psychological insights and perspectives (pp. 41-62). Thousand Oaks, CA: Sage.

Fentahun, N., Assefa, T., Alemseged, F. \& Ambaw, F. (2012). Parents' perception, students' and teachers' attitude towards school sex education. Ethiopian Journal of Health Sciences, 22(2), 99-106.

Fongkaew, W., Cupp, P. K., Miller, B., Atwood, K., Chamratrithirong, A., Rhucharoenpornpanich, O.,... Byrnes, H. (2012). Do Thai parents really know about sexual risk taking of their children: A qualitative study in Bangkok. Nursing \& Health Science, 14(3), 391-397.

DOI: 10.1111/j.1442-2018.2012.00703.x

Fongkaew, W., Fongkaew, K. \& Suchaxaya, P. (2011). Adolescent peer leader development in HIV prevention using youth-adult partnership with schools approach. Journal of the Association of Nurses in AIDS care, 18(2), 60-71. DOI: 10.1016/j.jana.2007.01.005

Goldman, J. D. (2011). An exploration in health education of an integrated theoretical basis for sexuality education pedagogies for young people. Health Education Research, 26(3), 526-541. DOI: 10.1093/her/cyq084

Im, Y. L. \& Park, K. M. (2014). Effects of sexuality education coaching program on sex-related knowledge and attitude among elementary school students. Journal of Korean Academy of Nursing, 44(1), 31-40. DOI: 10.4040/jkan.2014.44.1.31

Ingkathawornwong, T., Kritcharoen, S., Pol-in, K., \& Charoonsak, Y. (2007). Risk behaviour from sexual activity in female adolescents at vocational school. Songklanagarind Medical Journal, 25(6), 511-520.

Kim, J. L. \& Ward, L. M. (2007). Silence speaks volumes: Parental sexual communication among Asian American emerging adult. Journal of Adolescent Research, 22(1), 3-31. DOI: 10.1177/0743558406294916

Mchunu, G., Peltzer, K., Tutshana, B. \& Seutlwadi. (2012). Adolescent pregnancy and associated factors in South African youth. African Health Science, 12(4), 426-434. DOI: 10.4314/ahs.v12i4.5

McNeely, C. \& Blanchard, J. (2009). The teen years explained: A guide to healthy adolescent development. Baltimore: Johns Hopkins University Press. 
Morrison, L. (2004). Traditional in transition: Young people risk for HIV in Chiang Mai, Thailand. Qualitative Health Research, 14(3), 328-344. DOI: $10.1177 / 1049732303261624$

Muehlenhard, C. L. \& Quackenbush, D. M. (2011). The sexual double standard scale. In T. D. Fisher, C. M. Davis, W. L. Yarber, R. Bauserman, G. E. Schreer \& S. L. Davis (Eds.), Handbook of sexuality-related measures (pp.199200). Philadelphia: Taylor \& Francis.

Mulama, J. (2006). Education-Kenya: Too much too soon? Nairobi: Inter Press Service. National AIDS for Prevention and Alleviation Committee. (2010). UNGASS country progress report. January 2008-Decenber 2009. Bangkok: UNAID.

Phunkham, Y., Promprapat, P., Paisanautphong, K. \& Samukkeekarom, R. (2010). The study of sexual health promotion and prevention and youth health problem. Nontaburi: Bureau of reproductive health, Department of health, Ministry of Public Health.

Pusuwun, S., Wongyai. K. \& Leekuan, P. (2013). Behavior on perceived self-efficacy and sexual risk behavior among female adolescent. Nursing Journal, 40(4), 6879.

Ramiro, L. \& Matos, M. G. (2008). Perceptions of Portuguese teachers about sex education. Rev Saúde Pública, 42(4), 1-12.

Rasamimari, A., Dancy, B., Talashek, M. \& Park, C. G. (2007). Predictors of sexual behaviors among Thai young adults. Journal of the Association of Nurses in AIDS Care, 18(6), 13-21. DOI: 10.1016/j.jana.2007.08.001

Shtarkshall, R. A., Santelli, J. S. \& Hirsch, J. S. (2007). Sex education and sexual socialization: Roles for educators and parents. Perspectives on Sexual and Reproductive Health, 39(2), 1-10. DOI: 10.1363/3911607

Srisuriyawet, R. (2006). Psychosocial and gender based determinants for sexual risk behaviors among adolescents in school. (Unpublished doctoral dissertation), Faculty of Nursing, Chiang Mai University.

Tanasugarn, C., Kengkarnpanich, M. \& Kaeodumkoeng, K. (2012). Evaluation of comprehensive sex education program in high schools at the compulsory education level. Salaya, Thailand: Faculty of Public Health, Mahidol University.

The United Nations Population Fund Thailand (UNFPA). (2013). Minutes of the selected stakeholder consultation on the issue of adolescent pregnancy in Thailand. Paper presented at the Adolescent pregnancy Conference, Bangkok, Thailand.

Tietjen-Smith, T., Balkin, R. \& Kimbrough, S. (2014). Knowledge and teaching confidence of educators about sexual health topics. National Forum of Teacher Education Journal, 24(3), 1-9. 
Trinh, S., Ward, L. M., Day, K., Thomas, K. \& Levin, D. (2013). Contributions of divergent parent and peer sexual messages to Asian American college students' sexual behaviors. The Journal of Sex Research, 51, 208-220. DOI: $10.1080 / 00224499.2012 .721099$

VanLandingham, M. \& Trujillo, L. (2012). Recent changes in heterosexual attitudes, norms and behaviors among unmarried Thai men: A qualitative analysis. International Family Planning Perspectives, 28, 6-15. DOI: $10.2307 / 3088270$

Vivancos, R., Abubakar, I., Phillips-Howard, P. \& Hunter, P. R. (2012). Schoolbased sex education is associated with reduced risky sexual behaviour and sexually transmitted infections in young adults. Public Health, 127(1), 53-57. DOI: $10.1016 /$ j.puhe.2012.09.016

Vuttanont, U., Greenhalgh, T., Griffin, M. \& Boynton, P. (2006). Smart boys and sweet girls and sex education needs in Thai teenager: A mixed method study. The Lancet, 368(9552), 2068-2080. DOI: 10.1016/s0140-6736(06)69836-x 